Submitted to 1997 Particle Accelerator Conference,

Vancouver, B.C., Canada, May 12-16, $1997 *$

\title{
INSERTION DEVICE DEVELOPMENT IN THE X13 STRAIGHT OF THE NSLS X-RAY RING
} \author{
P. M. Stefan, S. Krinsky, C.C. Kao, G. Rakowsky, O. Singh, L. Solomon JUN 241997
NSLS, Brookhaven National Laboratory

$$
\text { CONF-97050 }
$$ \\ One of the most important studies conducted with the
} RECEIVED

Abstract

On the NSLS X-Ray Storage Ring, the X13 straight section and beamline have been used for insertion-device-related R\&D since 1990. We will describe three important projects: The Prototype Small-Gap Undulator (PSGU), the In-Vacuum Undulator (IVUN), and the Time Varying Elliptically Polarized Wiggler (EPW). The PSGU has successfully operated with a vertical aperture of only $3 \mathrm{~mm}$, with minimal reduction in electron beam lifetime. The EPW has successfully run during regular user operations while switching at either $2 \mathrm{~Hz}$ or $100 \mathrm{~Hz}$, with no adverse effects on other experiments. The IVUN project is a collaboration between NSLS and Spring-8, and installation is scheduled for May 1997.

\section{SMALL GAP UNDULATORS}

The PSGU $[1,2]$ combines a short-period $(16 \mathrm{~mm})$ undulator magnet and a variable-aperture vacuum chamber to produce high-brightness undulator light with a higher photon energy in the fundamental than would otherwise be possible in the $2.5 \mathrm{GeV} \mathrm{X}$-Ray Ring. Photons from the PSGU have been used to develop a coherent $\mathrm{x}$-ray beam for X-ray Photon Correlation Spectroscopy (XPCS). A coherent beam of $3 \times 10^{9}$ photons $/ \mathrm{sec}$ at $3 \mathrm{keV}(4.1 \AA)$ was produced through a $10 \mu \mathrm{m}$ pinhole.

The long low- $\beta$ straight sections of the NSLS X-Ray Ring (such as the X13 straight) are particularly well-suited for small-gap insertion devices. The stored electron beam focuses to a minimum dimension both in the vertical and in the horizontal at the center of the long straight. The PSGU is installed in the center of the straight section, and is quite short. The minimum-aperture-region of its variable vacuum chamber is $390 \mathrm{~mm}$ long, and the undulator magnet arrays are $320 \mathrm{~mm}$ long. In the regions closest to the electron beam, the PSGU vacuum chamber is thinned to $1 \mathrm{~mm}$. The magnet arrays are in air, located just outside the thinned vacuum chamber. The magnet gap is always at least $3 \mathrm{~mm}$ greater than the vertical aperture of the vacuum chamber for the electron beam. PSGU measured the reduction in the electron beam lifetime as the variable vacuum chamber aperture was reduced. The results are illustrated in Figure 1. The lifetime was essentially unaffected to a full aperture of $4 \mathrm{~mm}$, but then started to decrease. In a practical sense, an aperture of about $3 \mathrm{~mm}$ is operationally acceptable, since the overall lifetime reduction is small.

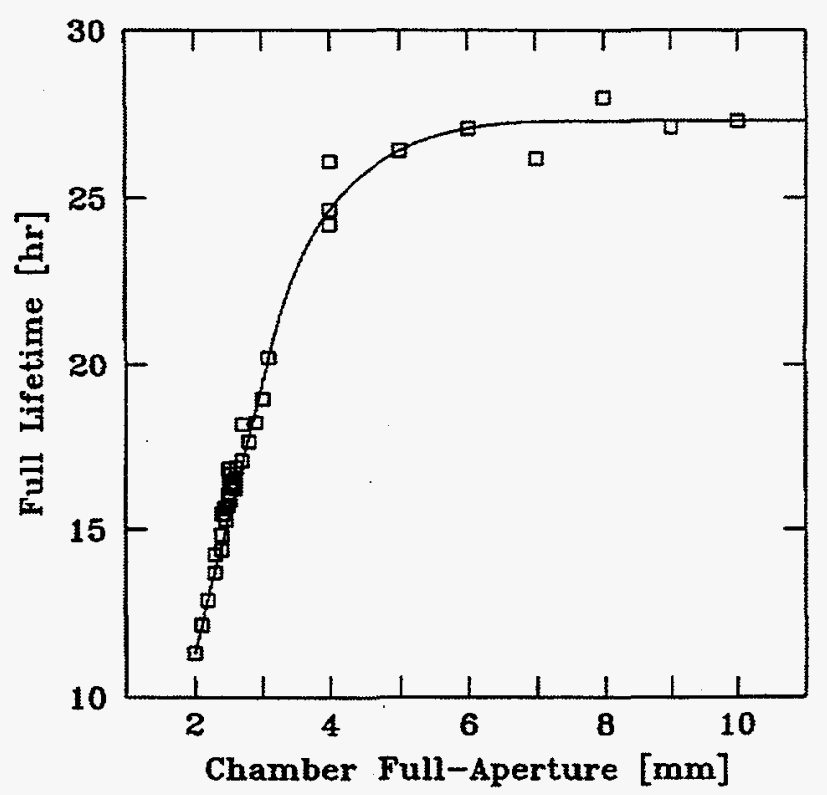

Figure 1: Stored beam lifetime as a function of the electron beam aperture presented by the PSGU vacuum chamber, at $220 \mathrm{~mA}$. The line drawn is a guide for the eye.

*Work supported by the Department of Energy, contracts DE-AC03-76SF00515 and DE-AC02-76CH00016 
In order to take full advantage of the ability to run with a $3 \mathrm{~mm}$ aperture, we are pursuing an in-vacuum undulator project (IVUN). This is a logical extension of the PSGU, with the variable vacuum chamber eliminated, and the undulator magnet arrays placed directly in the storage ring vacuum. For IVUN, the magnet gap and the corresponding electron beam aperture are very nearly the same dimension. A comparison between the parameters of the PSGU and IVUN is presented in Table 1.

\begin{tabular}{||l|l|c||}
\hline \multicolumn{2}{|c|}{ Table 1. PSGU/IVUN Comparison } \\
\hline & PSGU & IVUN \\
Period & $16 \mathrm{~mm}$ & $11 \mathrm{~mm}$ \\
NominalMagnet Gap & $6.0 \mathrm{~mm}$ & $3.3 \mathrm{~mm}$ \\
Corresponding Max. & $3.0 \mathrm{~mm}$ & $3.0 \mathrm{~mm}$ \\
Beam Aperture & & \\
Peak On-Axis Field & $0.623 \mathrm{~T}$ & $0.678 \mathrm{~T}$ \\
hv ${ }_{1 \text { out }},\left(\lambda_{1 \text { out }}\right)$ & $2.77 \mathrm{keV}$ & $4.64 \mathrm{keV}$ \\
& $(4.48 \AA)$ & $(2.67 \AA)$ \\
\hline
\end{tabular}

The IVUN design goal is for a photon output at $4.6 \mathrm{keV}$ $(2.7 \AA)$ in the fundamental, with high flux at the second and third harmonics, at a magnet gap of $3.3 \mathrm{~mm}$. Experiments spanning the whole spectrum of synchrotron-light applications, from spectroscopy and diffraction to microscopy and scattering, can benefit from this highbrightness, high-flux source. In addition, the electron beam characteristics of the X-Ray Ring allow IVUN to produce good second-harmonic intensity on-axis, at just over 8 $\mathrm{keV}$, with a half-intensity bandwidth of over $2 \mathrm{keV}$. IVUN is being built in a collaboration between the NSLS and the Japanese SPring-8 Project. Our collaborators at SPring-8 worked on the first successful in-vacuum undulator and are fabricating the $11 \mathrm{~mm}$-period magnet arrays for IVUN. When installed in the X13 straight section, IVUN will replace the PSGU,which is now situated at the center of the straight. Studies are planned to begin in the Summer of 1997.

\section{TIME VARYING ELLIPTICALLY POLARIZED WIGGLER}

The Time Varying Elliptically Polarized Wiggler (EPW) [3] produces elliptically-polarized light on axis, with the sense of rotation of the field vectors, i.e. the helicity, alternating at up to $100 \mathrm{~Hz}$. The EPW, as originated by Yamamoto and Kitamura [4], consisted of permanent magnet wigglers with crossed fields capable of generating circularly polarized radiation with higher harmonics on the wiggler axis. In our device, the horizontal permanent magnet structure has been replaced by an $A C$ electromagnet wiggler, in order to modulate the helicity. The EPW was built in a collaboration between the NSLS, the APS at Argonne National Lab, and the Budker Institute of Nuclear Physics at Novosibirsk. Usable fluxes of photons are available from $100 \mathrm{eV}$ to $10 \mathrm{keV}$, with the measured degree of circular polarization exceeding $50 \%$. Such a source is extremely useful for circular dichroism studies of both magnetic materials and materials with natural optical activity. The stable alternation of the helicity, at frequencies up to $100 \mathrm{~Hz}$, is an extremely powerful aspect of the source. This allows gating or lockin techniques to separate the responses of the sample to opposite helicities. When a lock-in amplifier is used, any steady-state or background signals are summarily removed from the start, since the lock-in only detects the signals which follow the EPW reference signal

The EPW was installed in December 1994, commissioned during Spring 1995 at an operating frequency of $2 \mathrm{~Hz}$, and became operational subsequently [5]. Utilizing trim coils at the wiggler ends and the high-precision orbit measurement system of the NSLS X-Ray Ring, the residual orbit motion was reduced to a level below $0.5 \mu \mathrm{m}$ [6]. No adverse effects on other experiments have been observed. The degree of circular polarization of the radiation from the wiggler was characterized by making Magnetic Circular Dichroism (MCD) measurements using the X13A soft-Xray beamline [7]. For values of the vertical deflection parameter, $\mathrm{K}_{x}$, of 1.2 and 1.6, the MCD effects at the $\mathrm{Fe} \mathrm{L}_{2.3}$ edges indicated a degree of circular polarization of $60 \%$ and $75 \%$, respectively, in good agreement with calculated values. Experimental programs based on the device, including MCD, Natural Circular Dichroism, and Resonant Magnetic Scattering, have also started. As an example, very small MCD effects near the $\mathrm{Cr} \mathrm{L}_{23}$ edges were observed in a series of $\mathrm{Co}-\mathrm{Cr}$ alloys (a promising candidate for a high-density perpendicular magnetic recording medium) by a collaboration of the Naval Research Laboratory, AT\&T, and the NSLS [8]. From these results, the $\mathrm{Cr}$ in the alloys was found to be polarized, and the induced $\mathrm{Cr}$ moment aligned anti-ferromagnetically with respect to that of the neighboring Co. These results also showed that MCD effects much smaller than $1 \%$ can be easily detected with the EPW, as illustrated in Figure 2. To fully utilize the EPW, a new soft $x$-ray spherical grating beamline and a double-crystal x-ray monochromator are being constructed, and will be operational in fiscal year 1997. Operations are now underway utilizing the EPW switching at $100 \mathrm{~Hz}$ and $2 \mathrm{~Hz}$, and commissioning at $23 \mathrm{~Hz}$ is underway. 
CoCr Magnetic Recording Media
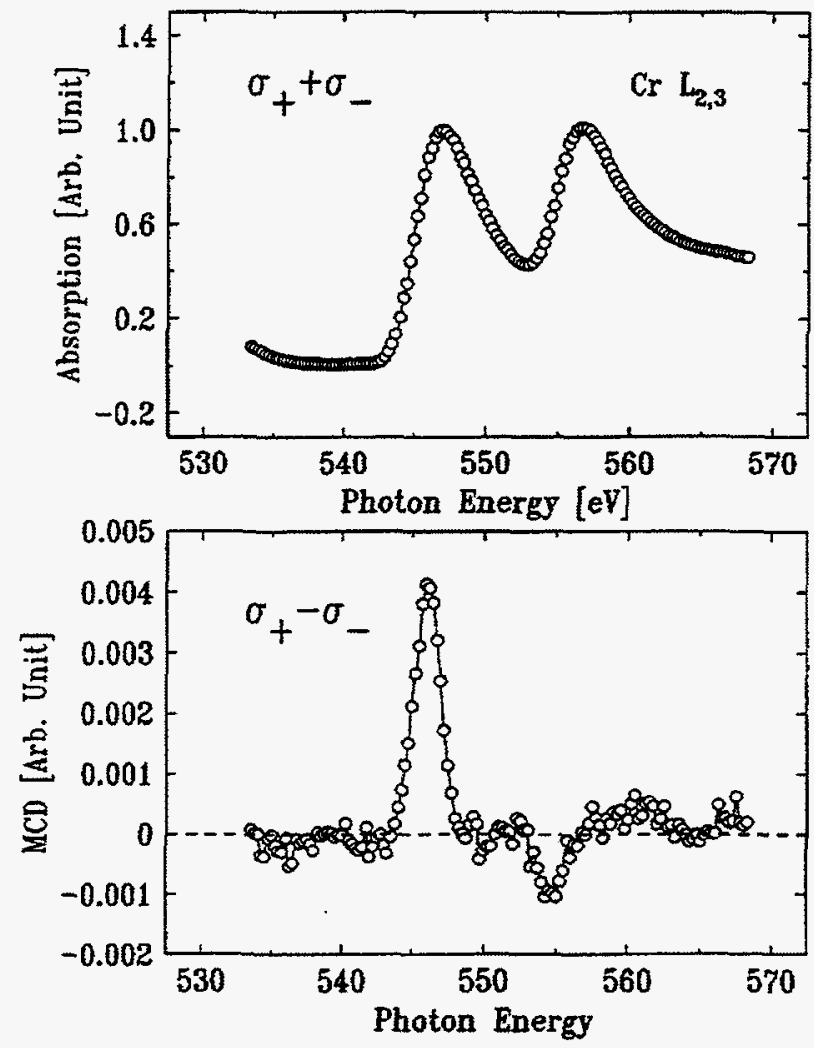

Figure 2: Magnetic Circular Dichroism (MCD) effects near the $\mathrm{Cr}_{2,3}$ edges in a series of $\mathrm{Co}-\mathrm{Cr}$ alloys [8]. From these results, the $\mathrm{Cr}$ in the alloys was found to be polarized, and the induced $\mathrm{Cr}$ moment aligned anti-ferromagnetically with respect to that of the neighboring $\mathrm{Co}$. The $\mathrm{MCD}$ effect illustrated is much smaller than $1 \%$.

\section{ACKNOWLEDGEMENTS}

Work performed under the auspices of the U.S. Department of Energy under contract DE-AC02-76CH00016.

\section{REFERENCES}

[1] P.M. Stefan, L. Solomon, S. Krinsky and G Rakowsky, Proc. 1991 Part. Accel. Conf., San Francisco, CA, p. 2542, (1991).

[2] P.M. Stefan, S. Krinsky, G. Rakowsky and L. Solomon, Proc. 1995 Part. Accel. Conf., Dallas, TX, p. 2435, (1995).

[3] A. Friedman, S. Krinsky and E. Blum, "Polarized Wiggler for NSLS X-Ray Ring: Design Consideration", Informal Report, BNL 47317, (1992); E.Gluskin, et al., Proc. 1995 Part. Accel. Conf., Dallas, TX, (1995).

[4] S. Yamamoto and H. Kitamura, Japan J.of Appl. Phys., 26, p.L1613, (1987).

[5] S. Krinsky, and C.-C. Kao, Synchrotron Radiation News, 8, 38, (1995).

[6] O. Singh, S. Krinsky, P.M. Ivanov and E.A. Medvedko, Proc. 6th Int. Synch. Rad. Instrum. Conf., Argonne, Il, October 1995.

[7] K.J. Randall, Z. Xu, E. Gluskin, I. McNulty, R. Dejus, S. Krinsky, O. Singh, C.-C. Kao, E.D. Johnson, C.T. Chen, and G. Meigs, J. Electron Spectroscopy and Related Phenomena, 80, 433, (1996).

[8] K.M. Kemner, V.G. Harris, V. Chakarian, Y.U. Idzerda, W.T. Elam, C.-C. Kao, Y.C. Feng, D.E. Laughlin, and J.C. Woicik, J. Appl. Phys. 79, 5345, (1996), Proceedings of the 40th Annual Conference on Magnetism and Magnetic Material Nov. 6-9, 1995 Philadelphia.

\section{DISCLAIMER}

This report was prepared as an account of work sponsored by an agency of the United States Government. Neither the United States Government nor any agency thereof, nor any of their employees, makes any warranty, express or implied, or assumes any legal liability or responsibility for the accuracy, completeness, or usefulness of any information, apparatus, product, or process disclosed, or represents that its use would not infringe privately owned rights. Reference herein to any specific commercial product, process, or service by trade name, trademark, manufacturer, or otherwise does not necessarily constitute or imply its endorsement, recommendation, or favoring by the United States Government or any agency thereof. The views and opinions of authors expressed herein do not necessarily state or reflect those of the United States Government or any agency thereof. 


\section{DISCLAMMER}

Portions of this document may be illegible in electronic image products. Images are produced from the best available original document. 